\title{
RESEARCH
}

Open Access

\section{Parent-adolescent communication on sexual and reproductive health issues and its associated factors in Ethiopia: a systematic review and meta-analysis}

Maru Mekie $^{1 *}$ D, Dagne Addisu', Abenezer Melkie ${ }^{1}$ and Wubet Taklual ${ }^{2}$

\begin{abstract}
Background: Every year, 1.3 million young people reported to die from preventable causes of death. Parentadolescent communication on sexuality is critical in informing youth about risk and protective behaviors which in turn decrease the likelihood of involvement in risky sexual behaviors. This systematic review and meta-analysis was intended to assess the prevalence of parent-adolescent communication on sexual and reproductive health (SRH) issues and its associated factors in Ethiopia.

Methods: PubMed, EMBASE, HINARI, Google Scholar, and University repositories were used to search studies. Article search was conducted from May 20 to June 9, 2020. Critical appraisal of studies was conducted using NewcastleOttawa Quality Assessment Scale (NOS). Data analysis was conducted using Stata 11 software following the abstraction of data using a format prepared on Microsoft excel. The heterogeneity of studies was tested using Cochran ( $Q$ test) and $\mathrm{I}^{2}$ test statistics. Similarly, funnel plot and Egger's regression asymmetry were used to assess publication bias. Subgroup analysis was conducted based on study Regions and sample size.

Result: Fourteen studies with sample of 8018 adolescents were included in this systematic review and metaanalysis. The pooled prevalence of parent-adolescent communication on SRH issues in Ethiopia was found to be $45.18 \%$ (95\%, Cl, 32.23, 58.13\%). Adolescents' knowledge of reproductive health matters (OR $=2.91,95 \% \mathrm{Cl}: 1.21$, 7.01), believe on importance of discussion on SRH issues ( $\mathrm{OR}=4.18,95 \% \mathrm{Cl}: 2.63,6.65)$, had history of sexual exposure $(\mathrm{OR}=1.95,95 \% \mathrm{Cl}: 1.53,2.50)$, parents openness to discuss $\mathrm{SRH}$ issues $(\mathrm{OR}=3.39,95 \% \mathrm{Cl}:(2.48,4.62)$, and being female $(\mathrm{OR}=1.60,95 \% \mathrm{Cl}: 1.07,2.38)$ were the positive predictors of parent-adolescent communications on $\mathrm{SRH}$ issues.

* Correspondence: maru.mekie1@gmail.com

'Department of Midwifery, College of Health Sciences, Debre Tabor University, Debre Tabor, Ethiopia

Full list of author information is available at the end of the article

C C The Author(s). 2020 Open Access This article is licensed under a Creative Commons Attribution 4.0 International License, which permits use, sharing, adaptation, distribution and reproduction in any medium or format, as long as you give appropriate credit to the original author(s) and the source, provide a link to the Creative Commons licence, and indicate if changes were made. The images or other third party material in this article are included in the article's Creative Commons licence, unless indicated otherwise in a credit line to the material. If material is not included in the article's Creative Commons licence and your intended use is not permitted by statutory regulation or exceeds the permitted use, you will need to obtain permission directly from the copyright holder. To view a copy of this licence, visit http://creativecommons.org/licenses/by/4.0/ The Creative Commons Public Domain Dedication waiver (http://creativecommons.org/publicdomain/zero/1.0/) applies to the data made available in this article, unless otherwise stated in a credit line to the data. 


\begin{abstract}
(Continued from previous page)
Conclusion: The prevalence of parent-adolescent communication on SRH issues was found to be low. Knowledge of adolescents about reproductive health matters, believe on the importance of discussion on reproductive health issues, history of sexual exposure, parents' openness to discuss SRH issues, and being female were found to be the positive predictors of parent-adolescent communication on SRH issues in Ethiopia. The finding our study indicated that evidence based education about reproductive health matters could significant to improve adolescent parent communication on $\mathrm{SRH}$ issues.
\end{abstract}

Keywords: Parent-adolescent communication, SRH, Prevalence, Systematic review, Meta-analysis

\section{Introduction}

Adolescent population accounts for a quarter of the global population and more than $70 \%$ resides in low income countries [1]. Time of adolescence is a key phase of human development. The rapid biological and psychosocial changes that take place during the second decade affect every aspect of adolescents' lives. Period of adolescence is an important time for laying the foundations of good health in adulthood if appropriate and adolescent tailored health strategies are established. Biological maturity usually precedes psychosocial maturity in which most adolescents try to do experimentation what they have observed around [2,3].

Adolescents are portion of population who are not served well by the existing health services. In order to have universal health coverage following the post 2015, it is important to ensure that the adolescent segment of the population receives adequate attention [3]. Many adolescents are reported to die prematurely due to accidents, suicide, violence, pregnancy related complications, and other reproductive illnesses that are either preventable or treatable through provision of adolescent tailored reproductive health services [2, 4]. According to WHO report, 1.3 million youth population reported to die every year from preventable causes of death [5]. Adolescent population are disproportionately affected by $\mathrm{Hu}-$ man Immuno- Deficiency Virus (HIV)/ (Acquired Immuno-Deficiency Syndrome (AIDS), and other reproductive health problems. Eighty-two percent of the estimated 2.1 million adolescents aged 10-19years living with HIV were in Sub-Saharan Africa (SSA) as of the 2012 report in which $58 \%$ of them were females. The review indicated that comprehensive knowledge about HIV, condom use, HIV testing, and antiretroviral treatment coverage remain low in most low income countries [6]. Globally, about 16 million women 15-19 years old give birth each year. Ninety-five percent of these births occur in low- and middle-income countries [2].

In Ethiopia, more than $60 \%$ of the population are under 24 years of age. On the other hand adolescent population (age 10-19 years) accounts the quarter of the total Ethiopian population which demands large investment in reproductive health [7]. Youth population who have limited access to quality youth friendly services are at increased risk of negative reproductive health outcomes. The Federal Ministry of Health of Ethiopia (FMoH) has established National adolescent and youth reproductive health strategy to improve the health of young population through training of health care providers at all levels, mobilizing resources to ensure continuous supplies of commodities, engagements partners, and communities to increase demand and knowledge of adolescents and youth reproductive health services [8]. However, adolescents and youth reproductive health has not been improved and reproductive health problems are continue to be a problem among young people in Ethiopia.

Parent-adolescent communication on sexuality is critical in informing young people about risk and protective behaviors which in turn decrease the likelihood of involvement in risky sexual behaviors $[9,10]$. Parents are one of the primary stakeholders who can play important roles in protecting adolescents from risky sexual behaviors such as unsafe sex, unwanted pregnancy, substance use, and violence $[2,3,11]$. Parents who are open enough for their young child with regards to sexuality have better communication which is important to reduce risky sexual behaviors such as early sexual initiation, unwanted pregnancy, and other reproductive health problems $[3,12]$.

Different factors are found to affect adolescent parent communication on sexual and reproductive health (SRH) issues. Cultural taboo, feel embraced to discuss on sexual issues, lack of communication skill, belief on sexuality, and knowledge on sexuality were some of the factors which affect adolescent parent communication on SRH issues [12-14]. Effective parent-adolescent communication is important to reduce adolescents' engagement in risky sexual behaviors. Many individual studies were conducted in different Regions of Ethiopia [12, 13, 15-17]. However, comprehensive evidence is lacking with regards to adolescent parent communication on $\mathrm{SRH}$ issues and its determinant factors. This systematic review and meta-analysis aimed to assess the pooled prevalence of adolescent parent communication and its determinant factors in Ethiopia. 


\section{Methods}

A systematic review and meta-analysis was conducted to estimate the prevalence of parent-adolescent communication on $\mathrm{SRH}$ issues and its determinant factors.

\section{Search strategy and study selection}

Both published and unpublished studies conducted about parent-adolescent communication about SRH issues and its determinant factors in Ethiopia were searched. Candidate studies reported in English language were identified through an online search of PubMed, EMBASE, HINARI, Google Scholar, and University repositories. Article search was conducted from May 20 to June 9, 2020. Different search strategies were used to exhaustively search studies to be included in this systematic review and meta-analysis. The search terms used for PubMed data base were: ("adolescent"[MeSH Terms] OR “adolescent"[All Fields]) OR "YOUNG CHILD” [All Fields]) AND ("parents"[MeSH Terms] OR "parents"[All Fields] OR "parent”[All Fields]) OR "guardian" [MeSH terms] OR guardians [MeSH terms] AND ("communication"[MeSH Terms] OR “communication”[All Fields]) AND ("sexual behavior"[MeSH Terms] OR ("sexual"[All Fields] AND "behavior"[All Fields]) OR "sexual behavior"[All Fields] OR "sexual"[All Fields]) AND ("reproductive health"[MeSH Terms] OR ("reproductive"[All Fields] AND "health"[All Fields]) OR "reproductive health"[All Fields]) AND "issues"[All Fields] AND ("ethiopia"[MeSH Terms] OR "ethiopia”[All Fields]).

Similarly, a separate search terms were used to search candidate studies for the systematic review and meta-analysis using Google scholar data base. The search terms used to search in Google Scholar were "Adolescent" OR "young child" AND "parent" OR "parents" OR "guardian" OR "guardians" AND "communication" OR "discussions" AND "sexual behaviors" or "sexual and reproductive health issues" AND "associated factors" AND "Ethiopia". Selection and exclusion of studies for the systematic review and metaanalysis was detailed using the Preferred Reporting

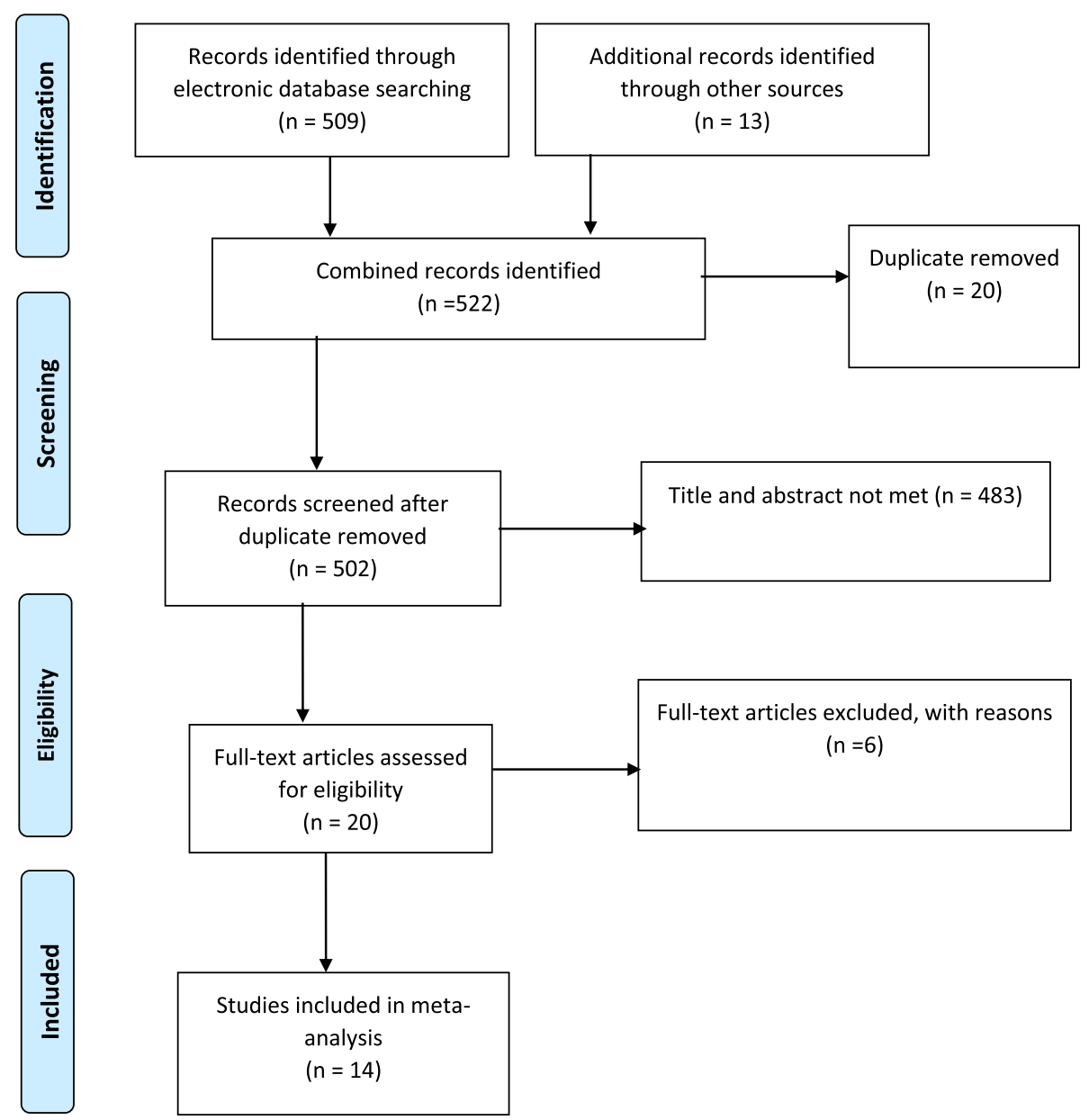

Fig. 1 PRISMA flow chart revealing study selection for systematic review and meta-analysis of parent-adolescent communication in Ethiopia 
Items for Systematic Reviews and Meta-Analyses (PRISMA) guidelines (Fig. 1).

\section{Inclusion and exclusion criteria}

Published and unpublished studies which reported magnitude of parent-adolescent communication on SRH and its determinants factors published/conducted from January 1, 2000 to June 9, 2020 were included.

\section{Study area}

Studies conducted in different Regions of Ethiopia were included in this systematic review and meta-analysis.

\section{Study design}

All studies included in this systematic review and metaanalysis were cross-sectional studies reporting findings from primary data.

\section{Language}

Studies reported in English language were included.

\section{Population}

Studies conducted among adolescent population about parental communication on SRH issues were included.

\section{Publication condition}

Peer reviewed published and unpublished studies were included for the systematic review and meta-analysis.

\section{Exclusion criteria}

Studies with no accessible full text, not reporting outcome of interest, and studies with different target population of our interest were excluded.

\section{Data abstraction}

Data abstraction was conducted using a format prepared in Microsoft excel. The data abstraction format was prepared by authors $\mathrm{MM}$ and DA for assessing parent-adolescent communication on SRH issues and its determinant factors. The abstraction format prepared on excel work book includes author name, publication year, Study Region, Study Zone, Study site, study design, study period, sample size, prevalence, and standard error of the prevalence. Similarly, the abstraction form includes factors affecting adolescent parent communication on SRH issues such as knowledge on SRH issues, believe on the importance of discussion on SRH issues, having sexual exposure, parents' openness to discuss SRH issues, and sex of the participants which could affect parent-adolescent communication on SRH issues.

\section{Measurement}

Parent-adolescent communication regarding sexual issues was the outcome of interest in this systematic review and meta-analysis. Parent-adolescent communication is considered when adolescents communicate at least two SRH issues with their parents.

\section{Data quality assurance}

Four reviewers, MM, DA, AM, and WT independently reviewed titles and abstracts of studies to be included in the systematic review and meta-analysis. Then studies were exported to Endnote 7 to manage duplications. Disagreements on inclusion and exclusion of studies were resolved through discussion between authors. Critical appraisal of studies was conducted using NewcastleOttawa Quality Assessment Scale (NOS). Studies with quality scores of $\geq 7$ out of 10 scale were considered as low risk for bias and included in the systematic review and meta-analysis (Table 1).

\section{Statistical analysis}

Microsoft excel was used for data extraction and analysis was performed using Stata version 11 software. Funnel plot and Egger's regression asymmetry test were used to assess publication bias. On the other hand, the prevalence and factors associated with parent-adolescent communication on SRH issues were presented using forest plots with 95\% confidence interval. Moreover, Cochran ( $\mathrm{Q}$ test) and $\mathrm{I}^{2}$ test were used to assess the random variations between primary studies [27]. In this systematic review and meta-analysis, heterogeneity was interpreted as an $\mathrm{I}^{2}$ value $=0 \%$ as no heterogeneity, $25 \%=$ low heterogeneity, $50 \%=$ moderate heterogeneity, and $75 \%=$ high heterogeneity [28]. To estimate the pooled prevalence of parent-adolescent communication on SRH issues and its associated factors, we have used both fixed and random models for studies with no heterogeneity and with heterogeneity respectively.

\section{Results}

A total of 522 studies (509 and 13) were retrieved through electronic data bases and other sources including university repositories. Twenty two studies were excluded due to duplicates, giving 502 studies. Following reviews of tittles and abstracts, 483 studies were excluded. Twenty full articles were screened for inclusion and six were excluded due to different reasons. Finally, 14 studies were selected for the systematic review and meta-analysis.

\section{Characteristics of included studies}

In this review, a total of 14 studies which reported parent-adolescent communication on SRH issues and determinant factors were included in the analysis. A total of 8018 adolescents were included in this review to 


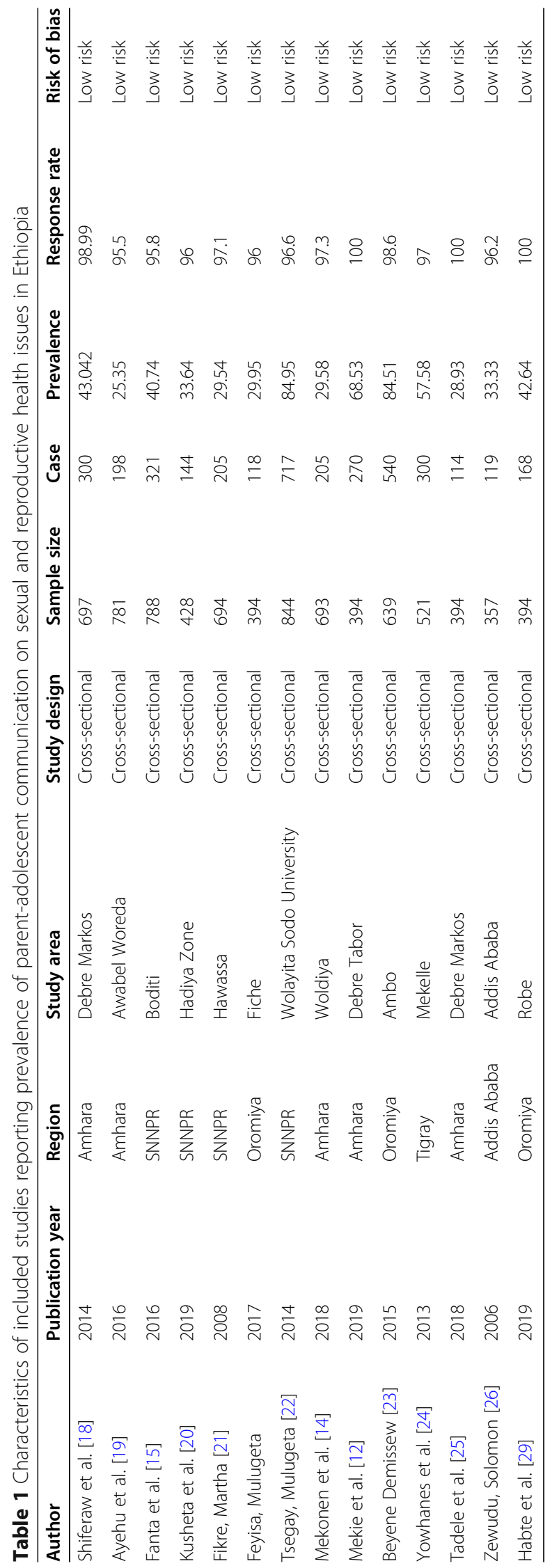


estimate the pooled prevalence of adolescent parent communication in Ethiopia. Studies published from January 2000 to June 2020 were included in the systematic review and meta-analysis. The included studies were conducted in 5 Regions of Ethiopia; Amhara Region [12, 14, 18, 19, 25], Oromiya Region ([23, 29]; Feyisa M: Parent-adolescent Sexual and Reproductive Health Communication and Associated Factors Among Secondary And Preparatory School Students In Fiche Town, North Shoa, Oromia Regional State, unpublished), Southern Nations Nationalities and People Region (SNNPR) [15, 20-22], Tigray Region [24] and the capital Addis Ababa [26] see detail (Table 1).

\section{Meta-analysis}

Prevalence of parent-adolescent communication in Ethiopia Fourteen studies were included to estimate the pooled prevalence of parent-adolescent communication on SRH issues ([12, 14, 15, 18-26, 29]; Feyisa M: Parent-adolescent Sexual and Reproductive Health Communication and Associated Factors Among Secondary And Preparatory School Students In Fiche Town, North Shoa, Oromia Regional State, unpublished). In this regard, the pooled prevalence of parent-adolescent communication on SRH issues in Ethiopia was found to be $45.18 \%$ (95\%, CI, 32.23, 58.13\%) (Fig. 2).

\section{Heterogeneity assessment of included studies}

A significant heterogeneity was observed between the included primary studies with I squared $=99.4 \%, P=0.001$ in computing the pooled prevalence of parent-adolescent communication on SRH issues. Hence, subgroup analysis was performed based on study Regions (Fig. 3) and sample size (Fig. 4).

\section{Sub group analysis of parent-adolescent communication on SRH issues based on study Region}

The subgroup analysis of the prevalence of parent-adolescent communication on SRH issues based on study Region indicated that there was variations in the prevalence of parent-adolescent communications between Regions with significant heterogeneity within studies (Fig. 3). The highest prevalence of parent-adolescent communication on SRH issues was reported to be the highest in Oromiya Region 52.40\% (95\%, CI: 15.97, 88.83\%) followed by SNNPR, and Amhara Region with respective

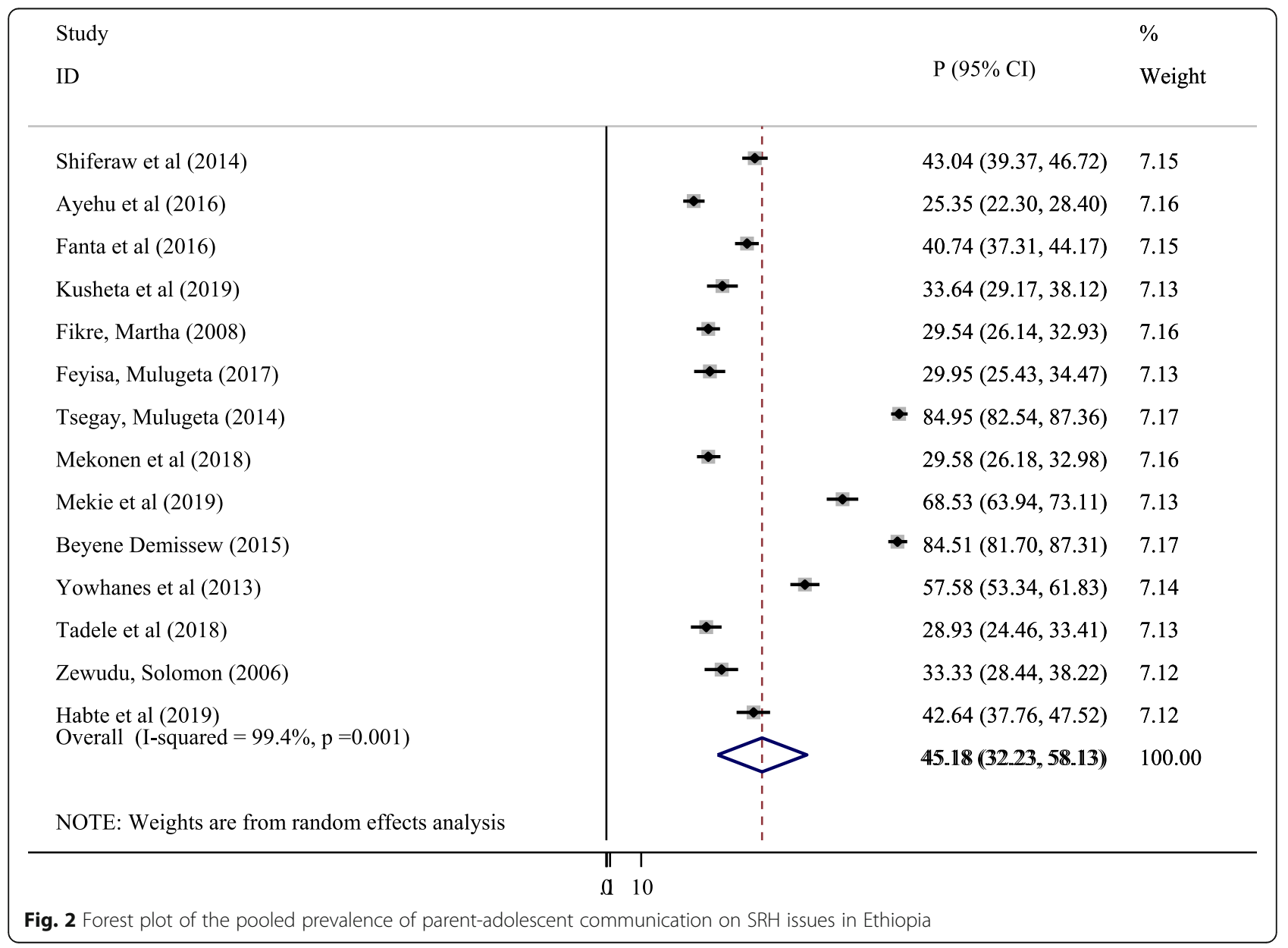




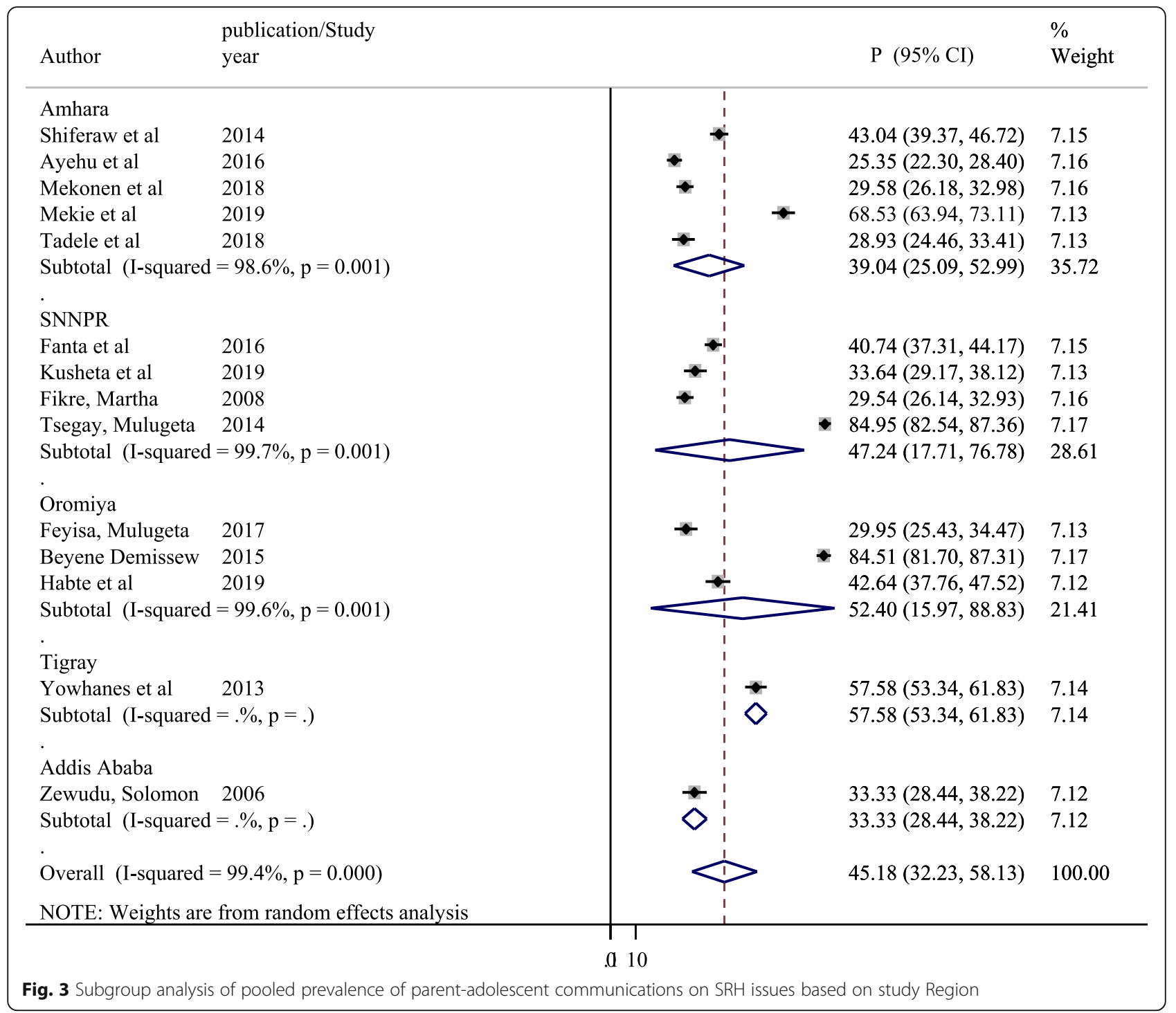

prevalence of $47.24 \%$ (95\%, CI: 17.71, 76.78\%) and 39.04\% (95\%, CI, 25.09, 52.99\%). However, a wide confidence intervals were found among studies in Oromiya Region and SNNPR. On the other hand, since the included studies in the meta-analysis were a few in Addis Ababa and Tigray, the subgroup analysis findings were not reported in comparison with other Regions.

\section{Subgroup analysis of prevalence of parent-adolescent communication on SRH issues based on sample size}

Subgroup analysis of prevalence of parent-adolescent communication on SRH issues based on sample size was performed by taking the mean sample size of the included studies as $\geq 527$ and $<572$ (Fig. 4). The subgroup analysis based on sample size indicated that the prevalence of parent-adolescent communication was found to be higher among studies with sample size of $\geq 527$
(49.42, 95\% CI: 30.69, 68.15\%) compared to studies with sample size of < 527 (39.50, 95\% CI: 27.34, 51.66\%,) with a significant heterogeneity between studies in both groups.

\section{Publication bias}

Funnel plot and Egger's asymmetry test were used to assess the symmetry of studies used to estimate the pooled prevalence of parent-adolescent communication on SRH issues (Fig. 5). The Egger's regression asymmetry test indicated that there was a minimal evidence of publication bias with $p$ value of 0.044 .

\section{Factors associated with parent-adolescent communication in Ethiopia}

In this systematic review and meta-analysis, knowledge on reproductive health matters $(\mathrm{OR}=2.91,95 \%$ CI:1.21, 7.01), believe on the importance of discussion 


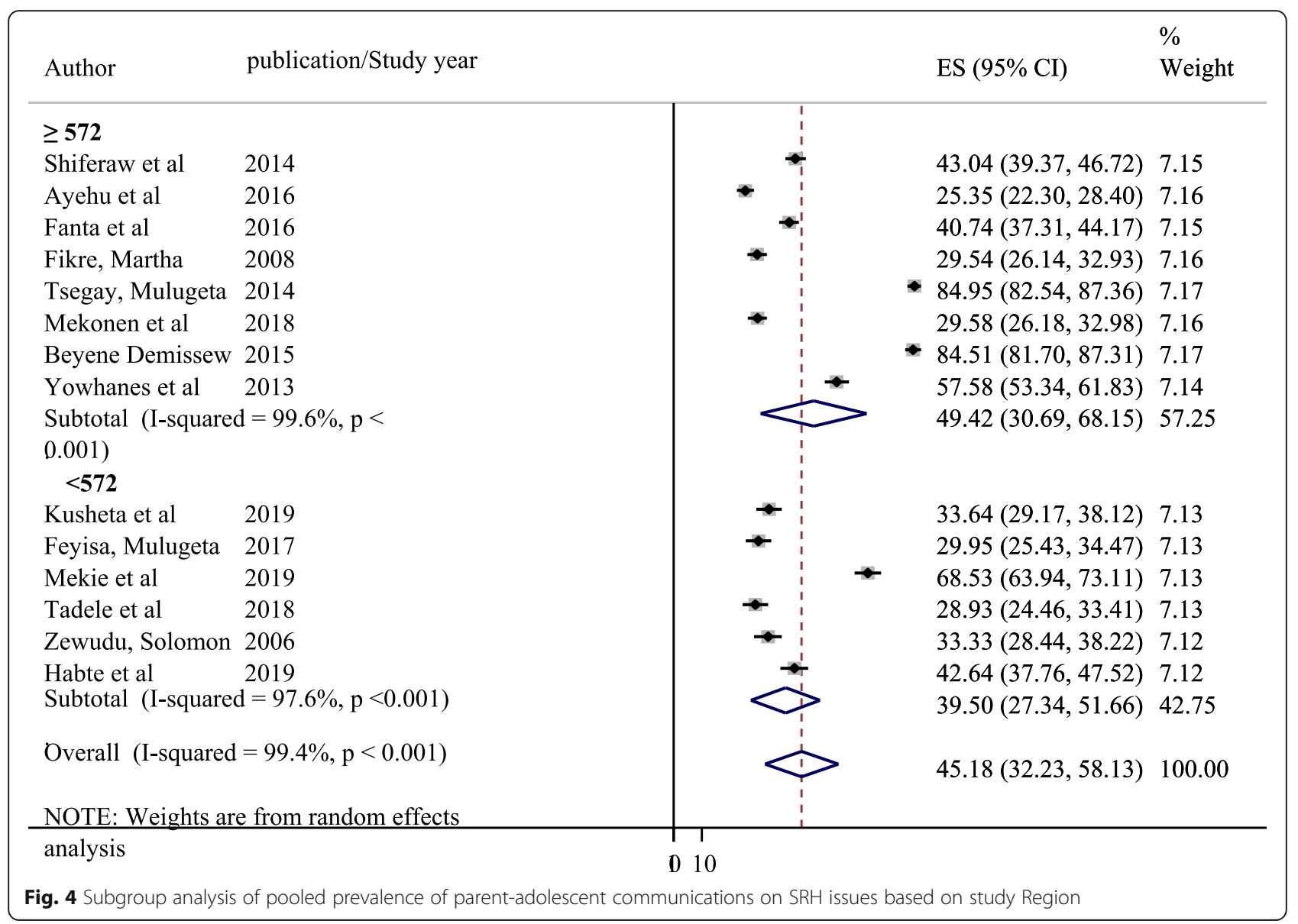

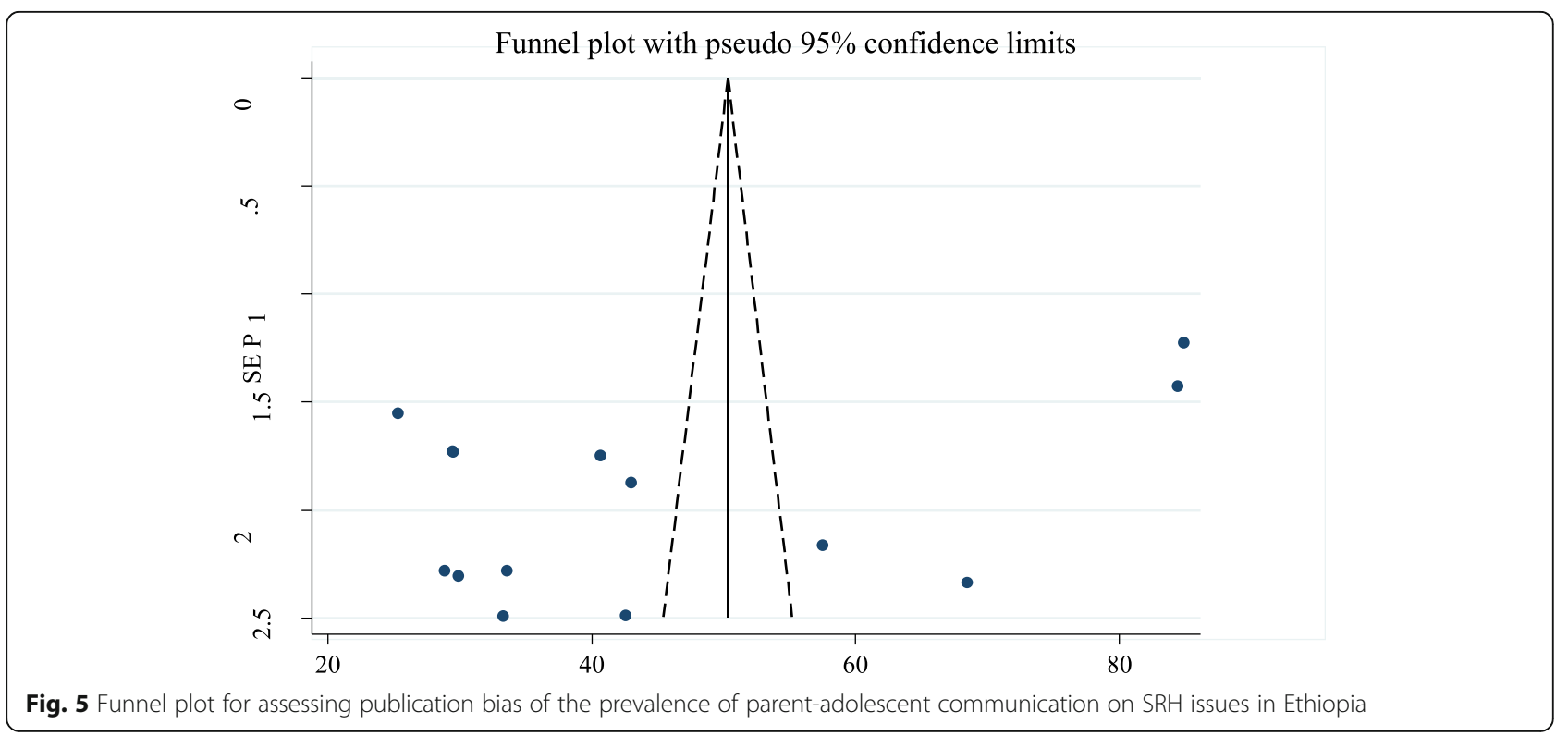


$(\mathrm{OR}=4.18,95 \%$ CI: 2.63, 6.65), history of sexual intercourse $(\mathrm{OR}=1.95,95 \% \mathrm{CI}: 1.53,2.50)$, parents' openness $(\mathrm{OR}=3.39,95 \% \mathrm{CI}$ : $(2.48,4.62)$, and being female adolescent $(\mathrm{OR}=1.60,95 \% \mathrm{CI}: 1.07,2.38)$ were significant predictors of parent-adolescent communications on $\mathrm{SRH}$ issues.

The association between knowledge on reproductive health matters and parent-adolescent communication on SRH issues

Three studies ([15, 25]; Feyisa M: Parent-adolescent Sexual and Reproductive Health Communication and Associated Factors Among Secondary And Preparatory School Students In Fiche Town, North Shoa, Oromia Regional State, unpublished) were incorporated in the analysis of the association between adolescents' knowledge on reproductive health matters and adolescent parent communication on SRH issues. Adolescents who have knowledge about reproductive health matters were 2.91 times more likely to communicate SRH issues with their parents compared with those who did not have knowledge (OR = 2.91, 95\% CI:1.21, 7.01) (Fig. 6).

\section{Believe on the importance of discussion on reproductive health matters and its association with communication on $\mathrm{SRH}$ issues}

The finding of our meta-analysis indicated that there was a statistically significant association between believe on the importance of discussion on reproductive health matters and parent-adolescent communications on SRH issues. Adolescents who believed on the importance of discussion on reproductive health matters were 4.18 times more likely to communicate SRH issues with their parents compared with those who did not believe on the importance of discussing sexual health $(\mathrm{OR}=4.18,95 \%$ CI: 2.63, 6.65). Six studies ([12, 14, 15, 18, 26]; Feyisa M:
Parent-adolescent Sexual and Reproductive Health Communication and Associated Factors Among Secondary And Preparatory School Students In Fiche Town, North Shoa, Oromia Regional State, unpublished) were included in the meta-analysis of the association between believe on the importance of discussion on reproductive health matters and parent-adolescent communications on SRH issues (Fig. 7).

The association between sexual exposure and parentadolescent communication on SRH issues

Four studies were included in the meta-analysis of the association between history of sexual intercourse and parent-adolescent communication on SRH issues [14, $18,23,26]$. Adolescents who had history of sexual exposure were 1.95 times more likely to communicate on $\mathrm{SRH}$ issues with their parents compared with adolescents who did not have sexual exposure (OR $=1.95,95 \%$ CI: 1.53, 2.50) (Fig. 8).

\section{The association between parents' openness and parent- adolescent communication on SRH issues in Ethiopia}

Three studies [12, 14, 21] were included in the analysis of parent-adolescent communication on $\mathrm{SRH}$ issues (Fig. 9). The odds of experiencing parent-adolescent communication on SRH issues were 3.39 times higher among participants whose parents were open enough to discuss SRH issues compared with counterparts $(\mathrm{OR}=$ 3.39, 95\% CI: $(2.48,4.62)$.

\section{Association between sex of the study participants and parent-adolescent communication on SRH issues}

Three studies [15, 23, 29] were used to analyze the association between sex of the study participants and parentadolescent communication on SRH issues (Fig. 10). The odds of having parent-adolescent communication

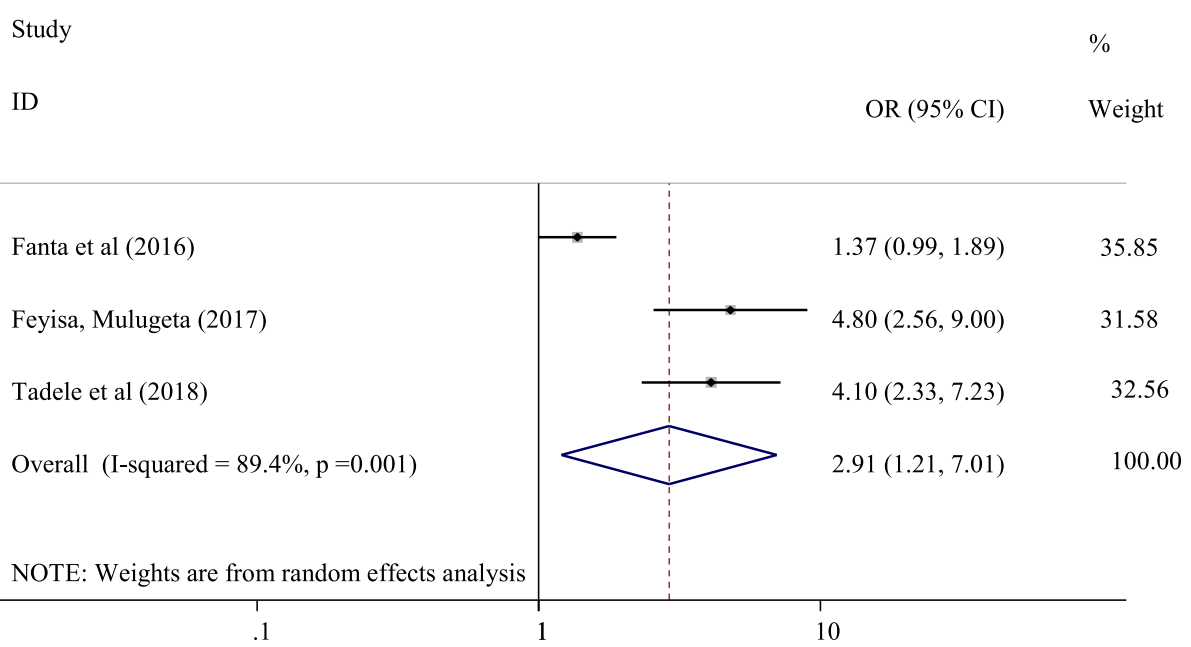

Fig. 6 Forest plot of the association between knowledge of reproductive health issues and parent-adolescent communication in Ethiopia 


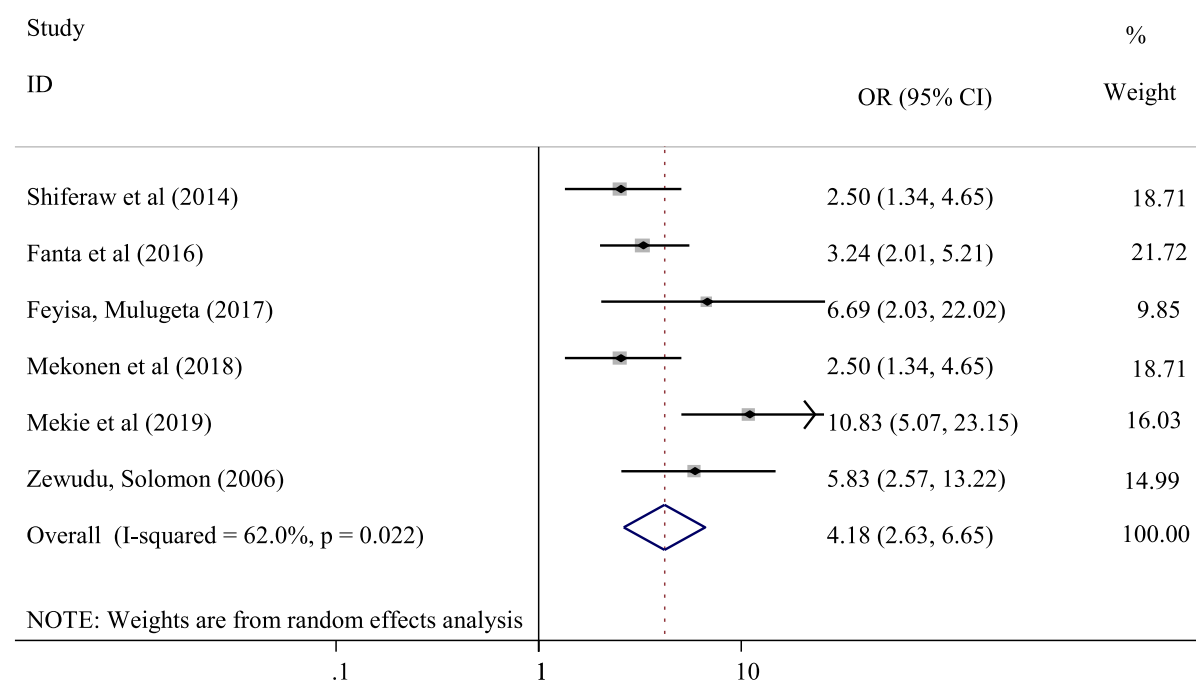

Fig. 7 Forest plot of the association between beleif on the importance of discussion on SRH issues and parent-adolescent communication in Ethiopia

on $\mathrm{SRH}$ issues were 1.60 times higher among female participants compared with males $(\mathrm{OR}=1.60,95 \% \mathrm{CI}$ : $1.07,2.38)$.

\section{Discussion}

Parent-adolescent communication promotes adolescents' self-esteem and boosting their confidence to prevent risky sexual behaviors since parents are the primary sexual educators for young child. Hence, encouraging adolescents to talk to their parents about sensitive issues is imperative [30]. This systematic review and meta-analysis was intended to examine the pooled prevalence of parent-adolescent communication on $\mathrm{SRH}$ issues and its determinant factors in Ethiopia.
The pooled prevalence of parent-adolescent communication on SRH issues in Ethiopia was found to be $45.18 \%$ (95\%, CI: 32.23, 58.13\%). The finding of our meta-analysis is found to be higher than a study conducted in Nigeria which reported 37.4, 32.5 and 9.5\% parent-adolescent communication about HIV/AIDS, family planning, and contraception respectively [31]. In a similar manner, the level of parent-adolescent communication on SRH issues in our study was found to be higher than a study conducted in Rwanda which reported no parent-adolescent discussion among $81 \%$ of the study participants [32]. The difference might be attributed to variation in measurement of the outcome variable and sociocultural condition of the society.

\section{Study}

ID

Shiferaw et al (2014)

Mekonen et al (2018)

Beyene Demissew (2015)

Zewudu, Solomon (2006)

Overall (I-squared $=0.0 \%, p=0.496)$
OR $(95 \% \mathrm{CI}) \quad$ Weight

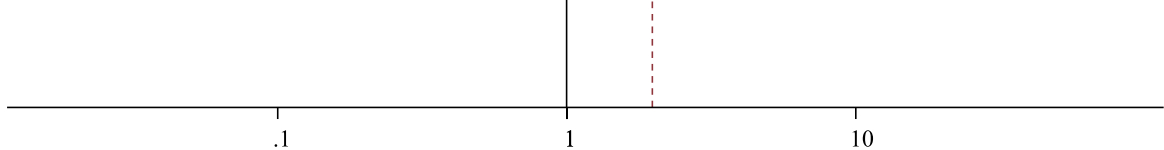

Fig. 8 Forest plot of the association between history of sexual intercourse and parent-adolescent communication on SRH issues in Ethiopia 


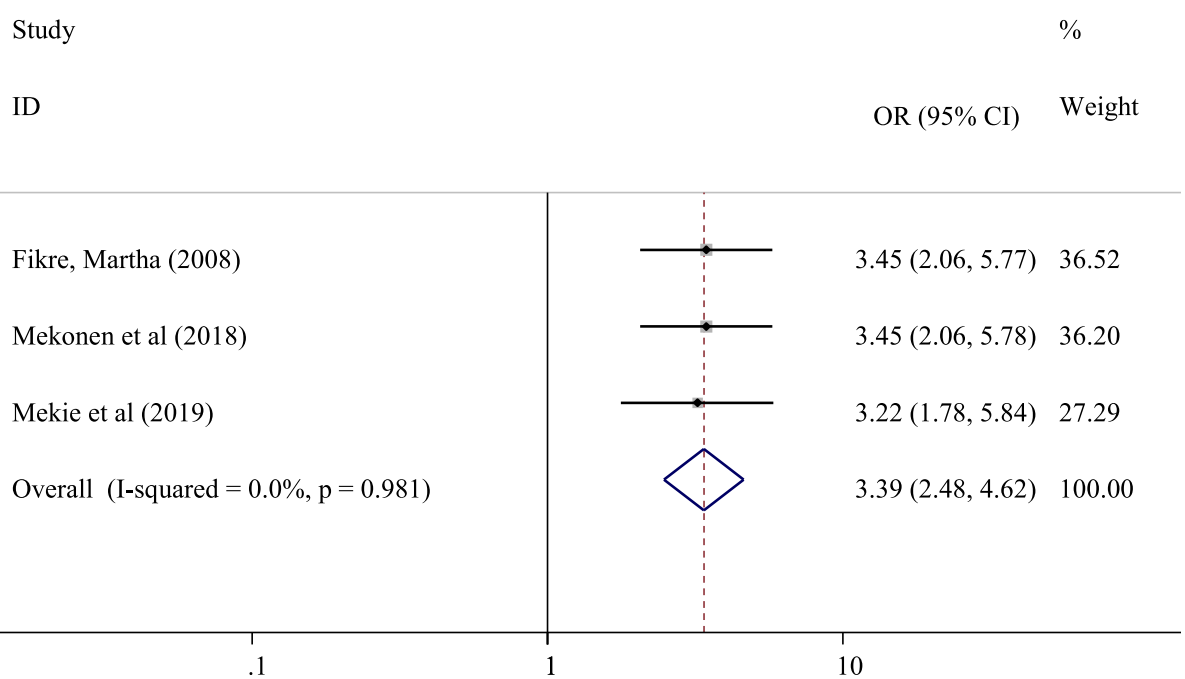

Fig. 9 Forest plot showing the association between parents' oppenness and parent-adolescent communication on SRH issues

Adolescents who did have knowledge about reproductive health matters were 2.91 times likely to communicate SRH issues with their parents compared with those who did not have knowledge about reproductive health issues $(\mathrm{OR}=2.91,95 \% \mathrm{CI}: 1.21,7.01)$. Knowledge on reproductive health matters was also reported to be statistically significant with parent-adolescent communications on SRH issues in an intervention study by Ford et al. The study indicated that adolescents in the sexual health intervention group reported a higher mean frequency score for parent-adolescent communication about sex compared with control counterparts [33]. Similarly, believe on the importance of discussion on SRH issues was found to be the predictor of parent-adolescent communication on $\mathrm{SRH}$ issues in in this systematic review and meta-analysis. Adolescents who believed on the importance of discussion on reproductive health matters were 4.18 times more likely to communicate SRH issues with their parents compared with those who did not believe on the importance of discussing sexual health (OR $=4.18,95 \% \mathrm{CI}: 2.63,6.65)$. Other studies indicated that parents are the initiators of parent-adolescent communications which indicates adolescents' low belief on the importance of parent-adolescent communication on SRH issues [30, 34]. Hence, evidence based education shall be provided to adolescents about the significance of parent-adolescent communication on SRH issues to improve parent-adolescent communication which in turn reduce adolescents' engagement in risky sexual behaviors.

Our systematic review and meta-analysis indicated that Adolescents who had history of sexual exposure were 1.95 times more likely to communicate on SRH issues with their parents compared with adolescents who did not have sexual exposure (OR $=1.95,95 \% \mathrm{CI}: 1.53,2.50)$.

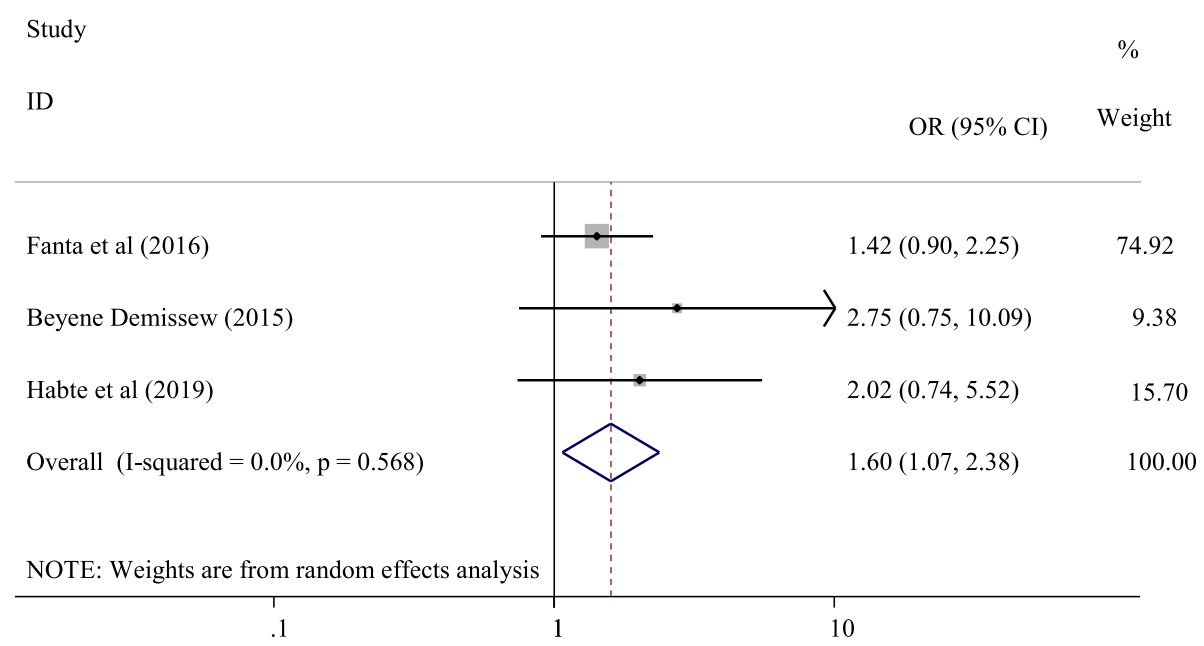

Fig. 10 Forest plot of the association between female sex and pareant-adolescent communication on SRH issues 
The finding of our study is supported by a study conducted in United States of America which reported 2.0 times higher odds of parent-adolescent communication on SRH issues among participants who ever had sexual intercourse compared with counterparts [35].

The odds of practicing parent-adolescent communication on SRH issues were found to be 3.39 times higher among participants whose parents were open enough to discuss SRH issues compared with counterparts $(\mathrm{OR}=$ 3.39, 95\% CI: $2.48,4.62)$. The finding of this systematic review and meta-analysis is supported by a study conducted in Johannesburg, South Africa which reported nonconducive environment for open discussions of SRH issues was a barrier for parent-adolescent communication on sexual issues [34]. Parents might not be open for their child in regards to sexual matters due to cultural belief that talking sexual matters with adolescents might facilitate sexual initiation and experimentations among adolescents. This belief need to be tackled by providing evidence based education for target audiences. Interventions targeting both adolescents and their parents may increase effectiveness in reducing negative adolescent sexual and reproductive health outcomes [36, 37].

This systematic review and meta-analysis found that sex of the study participant was a determinant factor for parent-adolescent communication on SRH issues. The odds of having parent-adolescent communication on SRH issues were 1.60 times higher among female participants compared with males (OR $=1.60,95 \%$ CI:1.07, 2.38). The finding of our systematic review and metaanalysis is supported by studies conducted in Nairobi, Kenya [38], Uganda [39], and Nigeria [31] which reported boys as less likely to discuss SRH issues with their parents than girls. In the same manner, a similar finding was reported in a meta-analysis by Widman et al. which reported a more pronounced protective role of parent communication among girls than boys with regards to safer sex behavior [40].

\section{Limitations of the study}

Despite it was intended to assess the magnitude of parentadolescent communications on SRH issues in Ethiopia, we could not get studies from all Regions of the country which might affect its representativeness. Small numbers of studies were used to analyze the pooled effect of some variables due to shortage of studies in the country. However, we have used both published and unpublished studies which might reduce the risk of publication bias.

\section{Conclusion}

The prevalence of parent-adolescent communication on $\mathrm{SRH}$ issues was found to be low. Knowledge of adolescents about reproductive health matters, believe on the importance of discussion on reproductive health issues, history of sexual exposure, parents' openness to discuss $\mathrm{SRH}$ issues, and being female were found to be the positive predictors of parent-adolescent communication on $\mathrm{SRH}$ issues in Ethiopia. The finding of this systematic review and meta-analysis indicated that education about reproductive health matters is significant to improve adolescent parent communication on SRH issues which in turn reduces reproductive health problems among adolescent population. Incorporation of reproductive health courses in secondary school curriculum would be the best option.

\section{Abbreviations \\ AIDS: Acquired Immuno-Deficiency Syndrome; HIV: Human Immuno- Deficiency Virus; NOS: Newcastle-Ottawa Quality Assessment Scale; SRH: Sexual and Reproductive Health; SNNPR: Southern Nations Nationalities and People Region; WHO: World Health Organization}

\section{Acknowledgments \\ Not applicable.}

\section{Authors' contributions}

MM participated in the conception, study selection, study methods, data abstraction, data analysis, and manuscript preparation. Whereas, DA, AM and WT were involved in study selection, data abstraction, Methods and revision of the final version of the manuscript. The final version of the manuscript is read and approved by all authors.

\section{Funding}

Not applicable.

\section{Availability of data and materials}

All relevant data are presented within the manuscript and the dataset used to reach conclusion can be assessable from the corresponding author on request.

Ethics approval and consent to participate

Not applicable.

\section{Consent for publication}

Not applicable.

\section{Competing interests}

The authors declared no competing interests.

\section{Author details}

'Department of Midwifery, College of Health Sciences, Debre Tabor University, Debre Tabor, Ethiopia. ${ }^{2}$ Department of Public Health, College of Health Sciences, Debre Tabor University, Debre Tabor, Ethiopia.

Received: 27 July 2020 Accepted: 5 October 2020

Published online: 30 October 2020

\section{References}

1. Tessema G, Laurence C, Melaku Y, Misganaw A, Woldie S, Hiruye A, et al. Trends and causes of maternal mortality in Ethiopia during 1990-2013: findings from the Global Burden of Diseases study 2013. BMC Public Health. 2017; 17:160.

2. Moghaddam H, Bahreini A, Abbasi M, Fazli F, Saeidi M. Adolescence health: the needs, problems and attention. Int J Pediatr. 2016;4(2):1423-38.

3. World Health Organization. Health for the World's Adolescents A second chance in the second decade: WHO; 2014. https://www.who.int/maternal_ child_adolescent/documents/second-decade/en/. Accessed June 2020.

4. Morris J, Rushwan $\mathrm{H}$. Adolescent sexual and reproductive health: the global challenges. Int J Gynecol Obstet. 2015;131(2015):S40-S2.

5. Mabaso T, Erogbogbo T, Toure T. Young people's contribution to the Global strategy for women's, children's and adolescents' health (2016-2030). Bull 
World Health Organization. 2016;94(5):312. https://doi.org/10.2471/BLT.16. 174714 .

6. Idele P, Gillespie A, Porth T, Suzuki C, Mahy M, Kasedde S, et al. Epidemiology of HIV and AIDS Among Adolescents: Current Status, Inequities, and Data Gaps. J Acquir Immune Defic Syndr. 2014; 66(Supplement 2):S144-53.

7. PMA/2020. Adolescents \& young women health brief, data from 2016, survey round 42016 .

8. Ministry of Health [Ethiopia]. National Adolescent and Youth Reroductive Health Strategy 2007-2015. Addis Ababa: Ethiopia Federal Democratic Republic of Ethiopia, Ministry of Health; 2007.

9. Cottrell L, et al. Gender-based model comparisons of maternal values, monitoring, communication, and early adolescent risk behavior. J Adolesc Health. 2007:41(4):371-9.

10. Yang $\mathrm{H}$, et al. Dynamic association between parental monitoring and communication and adolescent risk involvement among African- American adolescents. J Natl Med Assoc. 2007:99(5):517-24.

11. Terzian M, Andrews K, Moore K. Preventing multiple risky behaviors among adolescents: seven strategies (www.childtrends.org). Washington, DC: Child Trends; 2011.

12. Mekie M, Taklual W, Melkie A, Addisu D. Parental communication on sexual and reproductive health issues and its associated factors among preparatory school students in Debre Tabor, Northcentral Ethiopia: institution based cross-sectional study. BMC Research Notes. 2019;12:598.

13. Ayalew M, Mengistie B, Semahegn A. Adolescent - parent communication on sexual and reproductive health issues among high school students in Dire Dawa, Eastern Ethiopia: a cross sectional study. Reprod Health. 2014;11: 77.

14. Mekonen M, Dagnew H, Yimam T, Yimam H, Reta M. Adolescent-parent communication on sexual and reproductive health issues and associated factors among high school students in Woldia town, Northeastern Ethiopia. Pan Afr Med J. 2018:31:35.

15. Fanta M, Lemma S, Sagaro G, Meskele M. Factors associated with adolescent-parent communication regarding reproductive health issues, among high school and preparatory students in Boditi town, Southern Ethiopia: a cross-sectional study. Patient Intell. 2016;8:57-70.

16. Chane T, Cherie N. Parent-adolescent communication about sexual and reproductive health and associated factors among preparatory school students in Haiyk Town, North East Ethiopia. Res Med Eng Sci. 2018;5(2): 417-23.

17. Helamo D, Kusheta S, Bancha B, Habtu Y, Yohannes S. Utilization and Factors Affecting Adolescents and Youth Friendly Reproductive Health Services among Secondary School Students in Hadiya Zone, Southern Nations, Nationalities and Peoples Region, Ethiopia. Int J Public Health Saf. 2017;2(4):141.

18. Shiferaw K, Getahun F, Asres G. Assessment of adolescents' communication on sexual and reproductive health matters with parents and associated factors among secondary and preparatory schools' students in Debremarkos town, North West Ethiopia. Reprod Health. 2014;11:2

19. Ayehu A, Kassaw T, Hailu G. Young people's parental discussion about sexual and reproductive health issues and its associated factors in Awabel woreda, Northwest Ethiopia. Reprod Health. 2016;13(1):19.

20. Kusheta S, Bancha B, Habtu Y, Helamo D, Yohannes S. Adolescent-parent communication on sexual and reproductive health issues and its factors among secondary and preparatory school students in Hadiya zone, Southern Ethiopia: institution based cross sectional study. BMC Pediatr. 2019;19(1):9.

21. Fikir M. Assessment of parent-adolescent communication on sexual and reproductive health matters in Awassa town, SNNPR, Ethiopia; 2009.

22. Tsegay M. Assessment of sexual and reproductive health communication practice and associated factors among female undergraduate students of Wolaita Sodo University, Southern Ethiopia; 2015.

23. Beyene D. Assessment of parent-adolescents communication on sexual and reproductive health matters and associated factors among secondary and preparatory schools students in Ambo Town, Oromiya Region, Ethiopia; 2015.

24. Yowhanes Z, Berhe H, Hailu D. Assessment of Parent-Adolescent Communication about Sexual and Reproductive Health among High School Students in Mekelle Town, Northern Ethiopia. Glob J Med Res. 2016;6(2):9-37.

25. Taddele M, Jara D, Hunie A. Level of parent-adolescent communication on sexual and reproductive health issues and associated factors among debre markos preparatory school students, in debre markos town, east gojjam, zone, Ethiopia. Universal J Public Health. 2018:6(4):203-9.

26. Zewudu S. Assessment of adolescent parent communication concerning sexual and reproductive health; 2001

27. Rücker G, Schwarzer G, Carpenter JR, Schumacher M. Undue reliance on I 2 in assessing heterogeneity may mislead. BMC Med Res Methodol. 2008:8:79.

28. Higgins JP, Altman DG. Assessing risk of bias in included studies, Cochrane handbook for systematic reviews of interventions: Cochrane book series; 2008. p. 187-241.

29. Habte NM, Melaku AT, Alemayehu MT. Parent-adolescent communication on sexual and reproductive health matters and associated factors among secondary and preparatory school students in Robe town, Bale zone, Southeast Ethiopia. J Pub Health Int. 2019;1(4):1-15.

30. Family and Youth Service Bureaue. Parent-Child Communication 2016.

31. Ojebuyi B, Fagbamigbe A, Akinola O. Prevalence of and Factors Influencing Parent-Child Communication About HIV/AIDS, and Sexual and Reproductive Health Issues in Nigeria. SAGE Open. 2019;1 (12):1-12.

32. Bushaija E, Sunday F, Asingizwe D, Olayo R, Abong'o B. Factors that Hinder Parents from the Communicating of Sexual Matters with Adolescents in Rwanda. Rwanda J Health Sci. 2013;2(2):13-9.

33. Ford C, Mirman J, García-España J, Thiel M, Friedrich E, Salek E, et al. Effect of primary care parent-targeted interventions on parent-adolescent communication about sexual behaviorand alcohol use a randomized clinica trial. JAMA Netw Open. 2019;2(8):e199535.

34. Motsomi K, Makanjee C, Basera T, Nyasulu P. Factors affecting effective communication about sexual and reproductive health issues between parents and adolescents in zandspruit informal settlement, Johannesburg, South Africa. Pan African Med J. 2016;25(120).

35. Lantos H, Manlove J, Wildsmith E, Faccio B, Guzman L, Moore K. Parent-teen communication about sexual and reproductive health: cohort differences by race/ethnicity and nativity. Int J Environ Res Public Health. 2019;16:833.

36. Dittus PJ, Michael S, Becasen J, Gloppen K, PhD M, McCarthy K, et al. Parental Monitoring and Its Associations With Adolescent Sexual Risk Behavior: A Meta-analysis. Pediatrics. 2015;36(6):e1587-99.

37. Bastien S, Kajula L, Muhwezi W. A review of studies of parent-child communication about sexuality and HIV/AIDS in sub-Saharan Africa. Reprod Health. 2011:8:25

38. Maina B, Ushie B, Kabiru C. Parent-child sexual and reproductive health communication among very young adolescents in Korogocho informal settlement in Nairobi, Kenya. Reproductive Health. 2020;17(79).

39. Muhwezi W, Katahoire A, Banura C, Mugooda H, Kwesiga D, Bastien S, et al. Perceptions and experiences of adolescents, parents and school administrators regarding adolescent-parent communication on sexual and reproductive health issues in urban and rural Uganda. Reprod Health. 2015; 12:110.

40. Widman L, Choukas-Bradley S, Noar S, Nesi J, Garrett K. Parent-adolescent sexual communication and adolescent safer sex behavior: a meta-analysis. JAMA Pediatr. 2016:170(1):52-61.

\section{Publisher's Note}

Springer Nature remains neutral with regard to jurisdictional claims in published maps and institutional affiliations.

Ready to submit your research? Choose BMC and benefit from:

- fast, convenient online submission

- thorough peer review by experienced researchers in your field

- rapid publication on acceptance

- support for research data, including large and complex data types

- gold Open Access which fosters wider collaboration and increased citations

- maximum visibility for your research: over $100 \mathrm{M}$ website views per year

At $\mathrm{BMC}$, research is always in progress.

Learn more biomedcentral.com/submissions 